\title{
Negotiation of knowledge for coastal management? Reflections from a transdisciplinary experiment in South Africa
}

\author{
Louis Celliers (1D ${ }^{1,2}{ }^{凶}$, Dianne Scott ${ }^{3}$, Mvuselelo Ngcoya $^{4} \&$ Susan Taljaard ${ }^{1,5}$
}

Hybrid science-society approaches for knowledge production are often framed by a transdisciplinary approach. Most forms of "linear" progression of science informing policy or the "production" of knowledge as a one-way process are increasingly being challenged. This is also true for coastal and marine sciences informing decision-making to support sustainable development of coastal areas. From the early 2010s, South Africa had one of the most progressive and well-structured frameworks for the establishment of integrated coastal management (ICM) in order to achieve societal objectives for its valuable coastal area. Even so, the implementation of the legislation, policies and guidelines remain a challenge, especially at the local level in municipalities. This paper reports on a social experiment that was intended to examine the possibility for a new knowledge negotiation process to unsettle the highly structured, nested and regular policy process, which forms the basis of ICM in South Africa. This paper reflects on an experimental application of a participatory methodology known as a "competency group" to co-produce knowledge for coastal and marine management. The group members, a combination of codified, tacit and embedded knowledge holders, agreed to serve on a competency group and met on six occasions over a 12-month period in 2013. This group "negotiated" amongst themselves to achieve a common understanding of knowledge useful for the management of beach water quality on the Golden Mile, the prime beachfront of Durban, a South African city. The paper provides a novel lens into a potentially distinctive, challenging and imminently useful approach of co-producing knowledge for coastal governance, especially in a middle-income country where the social and political context is complex.

\footnotetext{
${ }^{1}$ Council for Scientific and Industrial Research, Natural Resources and the Environment, Durban, South Africa. ${ }^{2}$ Climate Service Center Germany (GERICS), Helmholtz-Zentrum Hereon, Hamburg, Germany. ${ }^{3}$ Environmental and Geographical Science Department, University of Cape Town, Cape Town, South Africa. ${ }^{4}$ School of Built Environment and Development Studies, University of KwaZulu-Natal, Durban, South Africa. ${ }^{5}$ Institute for Coastal and Marine Research, Nelson Mandela University, Port Elizabeth, South Africa. ${ }^{凶}$ email: louis.celliers@hereon.de
} 


\section{Introduction}

nowledge production ${ }^{1}$, the role and authority of science, trust in scientific findings and the contribution of civil society have become hot topics in academia, especially given the substantial socio-environmental challenges of the new century (Dewulf et al., 2020; Norström et al., 2020; Mach et al., 2020). The proliferation of knowledge co-production (Norström et al., 2020) signifies a shift from the authority of science being the sole supplier of disciplinary and multidisciplinary data and information for knowledge production. The notion that it is possible to produce "new kinds" of knowledge has gained power and visibility in contemporary scientific, public and political fora (Hulme, 2010; Romero-Lankao et al., 2018; Vera, 2018). Researchers across the disciplinary spectrum are experimenting with and reflecting on such knowledge production processes and methodologies (Hessels and van Lente, 2008; Arnott et al., 2020; Latulippe and Klenk, 2020). To this end, there has been a strong movement towards hybrid science-society approaches such as transdisciplinary knowledge generation (Vogel et al., 2016; Bremer and Meisch, 2017; Sachs et al., 2019).

Transdisciplinarity is a form of integrated and inclusive knowledge production with which to address wicked problems that arise in social-ecological systems (Max-Neef, 2005; Bernstein, 2015). It is considered a more democratic process for knowledge production, particularly for policy-making, and for enhancing sustainability (Callon, 1999; Whatmore and Landström, 2011; Polk, 2015; Bulkeley et al., 2018). It is collaborative and participatory, transformative, and transcends traditional disciplinary boundaries and hierarchical societal structures (Polk, 2015; Rosendahl et al., 2015; Lotz-Sisitka et al., 2015; Simon et al., 2018). Transdisciplinarity as an approach includes the participation and contributions from academia, state actors and nonstate actors such as, land managers, user groups, communitybased organisations, non-governmental organisations, business and the public (Choi and Pak, 2007; Stock and Burton, 2011; Polk, 2015).

The question arises whether or not transdisciplinarity can create an opportunity for improving the exchange and sharing of knowledge between science and society, and offer solutions for addressing pervasive social-environmental challenges (Klein, 2013; Lawrence and Després, 2004)? A "new and different kind of knowledge" (Callon, 1999; Whatmore, 2009; Ordner, 2017; Sachs et al., 2019) with which to respond to controversy. Callon's (1999) "knowledge co-production" is a process built up through social interactions and mutual learning, as groups struggle to collaboratively promote their definitions of, and solutions to, problems (Jagannathan et al., 2020; Turnhout et al., 2020).

It has been proposed that the social interaction and mutual learning in competency groups ${ }^{2}$ can "disrupt" established ideas on environmental controversies. The purpose of such disruption is to produce new ways of knowing (Swilling, 2014). Within a competency group, data and information from a variety of sources are freely shared, and the interactions in the group is devoid of substantial and debilitating power differences between members. How well are these co-production processes within competency groups transferable between different geographical and contextual settings e.g. from river to coastal systems? The proportionally compounded social-environmental challenges of coastal and marine systems have compelled scientists to also experiment with knowledge co-production in this setting (Jentoft and Chuenpagdee, 2009; Clarke et al., 2013; Cvitanovic et al., 2015).

Coasts exemplifies the complexity of social-environmental interactions. In order to incorporate science into policy for managing inherently complex coasts, it is necessary to integrate "scientific knowledge" with all "other data and information" from societal actors to produce a new type of knowledge (Whatmore,
2009; Nursey-Bray et al., 2014). It is important to note that we do not use "alternative" or "new" knowledge to mean the disputation of fact (Cann and Raymond, 2018; Rutjens et al., 2021), or the creation of alternative narratives to suite an agenda, i.e., in politics (Knight and Tsoukas, 2019). Alternative knowledge, as it is used in this paper, refers to "different ways of knowing", that scientific data and its interpretation as information is part of the body of knowledge needed for decision-making in complex socialecological systems. Knowledge is negotiated, produced, exchanged and co-produced or negotiated as civil society interacts with and, possibly, challenges scientific understandings of environmental controversies (Callon, 1999; Whatmore, 2009).

The aim of this study was to extend knowledge production beyond disciplinary, interdisciplinarity, applied and participatory research in a coastal setting of a large coastal metropolitan municipality called Durban, South Africa. It is a social experiment to examine the possibility of "new knowledge" co-production to unsettle established and often incomplete, unbalanced and unrepresentative stakeholder participation, in this instance, in the highly structured, nested and regular framework for integrated coastal management (ICM) in South Africa. This paper explores three propositions in relation to the aim above. It tests the appropriateness of "knowledge negotiation" as an appropriate approach to contribute new knowledge to support decisionmaking. Secondly, it evaluates the use of a "competency group" as a pragmatic alternative method to the established stakeholder participation and consultation approaches to implement ICM. Finally, it describes "alternative knowledge" with which to improve coastal governance and the implementation of ICM. The paper is structured to provide the methodological approach, present the results from the competency group process, test the validity of the three propositions and discuss the implication of the approach.

\section{Methodology}

Transdisciplinary co-production was undertaken through the experimental application of the competency group methodology. The methodology was based on the work undertaken in the United Kingdom where competency groups were set up to provide knowledge to inform flood alleviation (Whatmore, 2009; Whatmore and Landström, 2011; Lane et al., 2011; Lane, 2014). The purpose of the competency group was not participation per se, but rather knowledge production. The three types of knowledge used to select participants were tacit (experiential), embedded (technical, political, cultural), and codified (academic, professional) knowledge (van Ewijk and Baud, 2009). The methodology is outlined in Supplementary Fig. 1.

Study area and management context. South Africa boasts a progressive and well-structured nested framework for the establishment of ICM, an adaptive management process, in order to achieve societal objectives for its coastal area (Celliers et al., 2013; Glavovic, 2000; Glavovic and Boonzaier, 2007). Coastal management in South Africa is implemented using a structurally advanced and spatially nested ICM framework. Even so, the implementation of ICM legislation, policies and guidelines remain a challenge, especially at the local level in municipalities (Celliers et al., 2015; Rosendo et al., 2018; Sowman and Malan, 2018).

The study area was the central shoreline of the City of Durban, which forms part of the eThekwini Metropolitan Municipality, South Africa. This popular and internationally known urban beach extends from the Durban Harbour mouth to Mngeni Estuary, and is colloquially known as the "Golden Mile" 
(approximately seven kilometres in length). The Golden Mile is a multi-use space popular for recreation, tourism, sports, residential, environmental and business activities, both formal and informal. The shoreline is influenced by many engineering interventions including piers, storm water outlets, a world-class promenade, dune rehabilitation works, and a sand pumping process for beach maintenance. Not surprisingly, the equitable use of coastal resources associated with the Golden Mile is steeped in controversies and conflicts, given the legacy of the racial segregation of the Durban beachfront under the Apartheid regime.

Propositions, methodological steps and the transdisciplinary process. The methodology included a formulation phase (pilot workshops, competency group selection, selection of controversy), and a realisation phase (competency group and reflection meetings) and an evaluation phase (evaluation, data capture, management and analysis).

The formulation phase of the project resulted in the selection of a "competency group" and a list of "environmental controversies" of Durban's Golden Mile. The project was initiated by an inception meeting of the research team followed by a series of four pilot workshops (held July-November 2012. The project team also interviewed 22 people along a Golden Mile transect (October and November 2012), eight of which were tacit knowledge holders, who were also invited to attended the 4th pilot workshop. The purpose of the pilot workshops was to systematically identify and select "knowledge holders". There were two main criteria: (a) members had to be holders of knowledge (tacit, embedded or scientific, codified knowledge; see Supplementary Table 1); and (b) they had to live or work along, or were professionally invested in, the Golden Mile. The members of the competency group were not called "stakeholders" but rather "knowledge holders" as they were not there to represent themselves or any group's interests but rather to contribute their knowledge.

Eighty individuals attended one of the four pilot workshops. From the 80 participants a list of 30 participants were invited to become members of the Competency Group. (See Table S2 Supplementary Material for list of knowledge-holders attending the workshops $)^{3}$. Thirty-six percent $(36 \% ; 8)$ of the 22 individuals that attended at least one meeting held both codified and embedded knowledge while codified, embedded and tacit was, respectively, $10 \%(2), 41 \%$ (9) and $13 \%$ (3). Three additional people were later invited to participate in the experiment. Eight of the original 30 invited members never attended a meeting (See Table S2 Supplementary Material). The four pilot workshops were also used to identify and discuss the current "environmental controversies" along, or associated with the Golden Mile. Participants at the pilot workshops were given the task of identifying important social-environmental challenges of the Golden Mile.

During the realisation phase, the Competency Group met on six occasions over a 12-month period during 2013. This list of controversies identified in the pilot workshops was submitted to the Competency Group for further discussions and negotiations on priority. The initial agenda for the Competency Group was based on our understanding of the literature describing the functioning of such groups (Stassart, 2008; Lane et al., 2011), and the inception and pilot workshops. Subsequent agendas were determined by discussions in the Competency Group, as well as reflections of the research team. The research team, prepared agendas, kept minutes and notes, recorded the proceedings (video and audio), and also collected all outputs (such as presentations, flipcharts, data capture sheets, maps). Each meeting lasted ca. $6 \mathrm{~h}$ and had a thematic focus. The competency group meetings were facilitated by two social science members of the project team who were classified as codified knowledge holders. Group members were requested to make a commitment to the process, work collaboratively, and respect each other's knowledge contributions. The members were also requested to comply with the "rules of engagement", which included a philosophy of democratic participation and equal right to speak. It was also emphasised that members should participate in their individual rather than in a representative capacity. There was an agreement and assumption that all knowledge was equal. Dialogic rather than didactic methods were used to design the activities in order to enhance the receptivity of all participants (Scott and Taylor, 2019). The iterative process of post-meeting reflection and project evaluation continued for the duration of the project.

The evaluation phase took place simultaneously with the realisation phase. Data and information were captured as notes from project team meetings, competency group minutes, video recordings, group work outputs such as hand-drawn maps, and conceptual models. All knowledge products were acknowledged and captured as admissible observational project data of the experiment. While the competency group meetings produced the most and direct results, all activities were considered as dataproducing and samples are presented in the Results section below.

The learning process was iterative and part of a transdisciplinary approach to produce new knowledge, and to enhance receptivity among members of the group to other forms of knowledge that could contribute to coastal management (see Swilling, 2014). Knowledge produced was systematically and continually evaluated by the participants. During the final meeting Competency Group members were asked to reflect on the process of co-production and to critically evaluate the extent, volume and usefulness of the knowledge they had shared and gained. The reflections were in response to four questions and a facilitated discussion relating to the management burden and environmental knowledge controversies of the Golden Mile (Supplementary Tables 3 and 4).

The paper is qualitative in its approach. In order that all participants could engage with each other, a narrative approach was adopted and therefore the research is situated in a constructivist paradigm. A thematic analysis in relation to the theory was used to reflect the outcomes of the competency group process and its challenges.

\section{Results}

This section presents the knowledge controversies that were identified by the participants in the workshops and the competency group; the nature of the competency group process; and the knowledge produced.

Identification of knowledge controversies. Among the top environmental issues identified for the Golden Mile were those relating to beach water quality, sand pumping for beach maintenance, water pollution and the destruction and degradation of marine habitats. Important management issues that were identified included: a mismatch between maintenance of beach facilities and infrastructure and the demand for these services; a lack of stakeholder engagement in beach management, as well as conflicting management and political interests (Fig. 1). The most significant conflicts identified were between fisherman and surfers, bathers and boats; and the managing of anti-social and unsafe behaviour along the beachfront. Apart from exposing the complexity of the coastal environment, the workshops highlighted a need for a more radical approach to coastal governance. There was consensus among participants that current approaches 


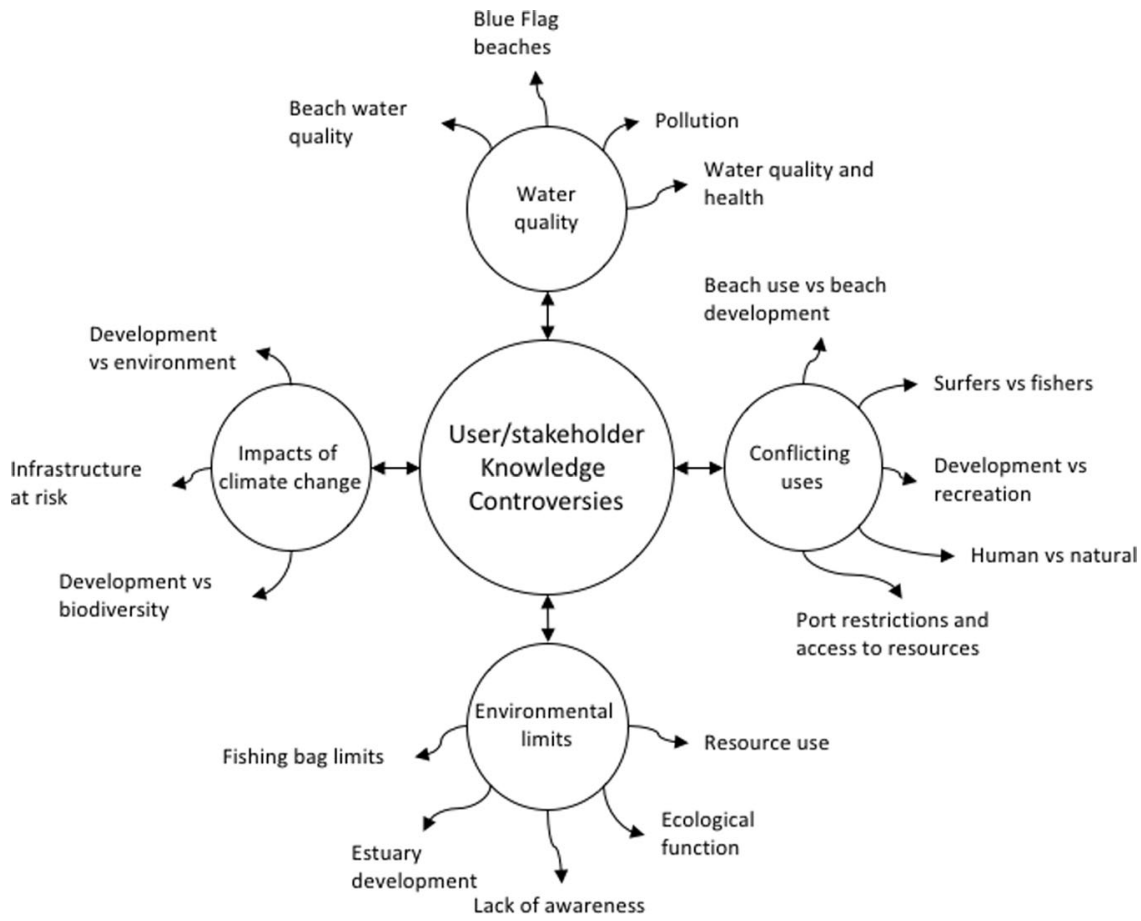

Fig. 1 Social-environmental knowledge controversies of the Golden Mile, Durban, South Africa as identified by the Competency Group (Competency Workshop No. 3, 30 May 2013).

to coastal governance in the municipality was deficient and that a more inclusive and cross-sector engagement was necessary to effect better management of the Golden Mile. Beach water quality as a topic presented the most significant contestation between scientific and beach user on issues such as value, local socialenvironmental impact, and technical measurement.

Competency group process. During the three years of the project there were two inception meetings $(2 \times 8 \mathrm{~h})$, four pilot workshops $(4 \times 6 \mathrm{~h}), 15$ local team meetings $(15 \times 2 \mathrm{~h})$, seven project team meetings $(7 \times 8 \mathrm{~h})$ and six competency group meetings $(6 \times 6 \mathrm{~h})$. The total time spent on issues relating to formulation, generation and evaluation easily exceeding $150 \mathrm{~h}$ of project time (Supplementary Table 2).

The agenda of the six competency group meetings were produced through continuous engagement, considering the content and discussion of previous meetings, and the reflections, observations and discussions by the research team in relation to the goals of the project (Table 1). The competency group was facilitated by the researchers with the expectation of a shift in "ownership" of the process over time.

Participation in the competency group meetings varied and 22 individuals attended at least one meeting and six at most (Supplementary Table 2). Women and individuals from previously disadvantaged communities were under-represented at $36 \%$ ( 8 in total) for both categories. There was a naïve intention that the competency group members would be equal contributors to knowledge about the "environmental controversies" the Golden Mile. This is explained in the discussions below.

Knowledge production. The six competency group meetings resulted in a large volume of data generated either directly by the actions and discussions which took place, or indirectly through the analytical processes of the project team (Table 2). The data were a combination of tacit, embedded and codified knowledge.

\section{Validity of the propositions}

Although guided by, and attempting to build on existing literature, the post-colonial developing country context (ongoing transformation with a legacy of structural inequality in South Africa), presented a meaningful challenge to achieving the objectives of the project. There are several frameworks that have provided guidance for the research team to evaluate the three propositions and aims of the study (see Mitchell et al., 2015; Polk, 2015; Scholz and Steiner, 2015).

Proposition 1 Conceptual framework of knowledge negotiation for coastal governance in the South African context

In their study of the environmental controversy of flooding in a small town in the United Kingdom, Lane et al. (2011) and Whatmore (2009) argued that if research is undertaken by a research team that involves scientists working with civil society actors, it is a transdisciplinary mode of knowledge production. This was the case here and the experiment co-generated knowledge to inform issues of beach water quality in the South African context according to the theoretical framework adopted. Callon's (1999) co-production model adopted for the competency group sought to promote mutual learning where people reached a point where they could expand their thinking to include other types of knowledge and different perspectives of a problem (see also Klein, 2014; Nagy et al., 2020; Polk, 2015). However, unexpected challenges arose during the process. Firstly, the co-ordination of the multidisciplinary research team leading an experimental transdisciplinary project provided a significant challenge due to diverging conceptual frameworks and subsequently how the project should be designed. This resulted in vigorous debates among the project team and endured throughout the project.

According to Braun (2015a) a competency group process should be situated and designed in relation to the societal context in which it takes place. In hindsight, it was realised that the competency group is a privileged space and difficult to design and sustain in an "under-privileged"space/society. Although South Africa became a democratic society in 1994, the levels of social and economic inequality remain very high. Twenty-five years 
Table 1 Topics on social-environmental knowledge controversies of the Golden Mile, Durban, South Africa as discussed by the Competency Group.

\section{Competency group} meeting topic

1. What is seen and what is valuable in the

study area?

\section{A transect walk of the} Golden Mile

3. Beach water quality

4. How water moves in the Durban Bight

\section{Management of a} complex space

6. New negotiated knowledge
Reasoning and objectives of the competency group meetings

The purpose was to gather individuals who hold different and potentially disparate knowledge of the study area to the negotiating table in order to foster collaboration and knowledge sharing relating to the environmental controversy. The objectives were to introduce group members to the research objectives and for them to begin to engage in social learning in order to foster collaboration between the different knowledge holders.

The second meeting took the form of an informal field trip, the objectives of which were to break down the "stakeholder engagement" mentality of participants and move them towards a more collaborative form of participation and dialogue. A number of members contributed informally to the discussions about the controversies apparent. The objective was also to continue to slow down the process of reasoning and to place responsibility for delivering knowledge in participants' hands.

This meeting was planned to present an opportunity to focus on the primary, selected environmental controversy-beach water quality where sea users rejected municipal measurements of beach water quality. The objective of this meeting was to explore different understandings of the issue and enhance members mutual understandings of other knowledges around the issue of beach water quality.

The fourth meeting was planned to introduce scientific data and information to the competency group through the presentation of a hydrological model study in the study area by an invited specialist (codified knowledge). The main objectives were to allow participants to reflect on the knowledge they have already produced in the previous meetings and to understand whether this knowledge was compatible with the findings of the scientific modelling study.

The fifth meeting provided an opportunity to explore the complex management space of the study area. This was done by way of presentations from institutions such as the eThekwini Municipality's Coastal Management and Tourism offices using a didactic method. The main objective of this meeting was to allow group members to take ownership for the knowledge they have produced and to co-produce a common long-term vision for the complex coastal space in a collaborative and negotiated manner. The final meeting presented itself as the last chance for the project team to reflect on the experiment and to understand how the process was experienced by the group's participants. The objective was to interrogate the understandings of the group members and to gain insights into their experiences of the process. This was achieved by asking members to answer four questions and a facilitated discussion (see Methodology).

\section{Knowledge-type rationale}

Encourage the contribution of experiential (tacit) knowledge and the legitimacy and diversity of different experiences.

The focus was on experiential knowledge but also contributions from professional perspectives.

Embedded, codified and tacit knowledge revealing a diversity of stated values of marine (and fresh) water (Supplementary Table 3).

Codified knowledge in the form of a numerical hydrodynamic model study on water circulation in coastal water along the study area.

Focus on embedded and contextual knowledge relating to the complex management space and requirements of a coastal city.

Reflection on the three knowledge types produced, their integration and their future value (Supplementary Tables 3 and 4). after the end of Apartheid there were very few black people $e^{5}$ that could be located who have an attachment to the beachfront, or have the depth of relevant knowledge to be selected as members of the group (Local Councillor, 12 March, 2013). Thus, the nonattendance of certain knowledge holders (e.g., the black councillor only attended the opening of the first meeting and a short part of 3rd meeting) was a critical issue resulting in an advertent racial bias in the knowledge that was produced. Another example of race influencing the research outcome was the fact that a group of black women cleaners withdrew their participation in meetings because of a white man whom they know as a member of the city's policing machinery that also attended.

The experimental nature of the competency group process operated outside of the municipal institutions with only tenuous relationships to functional units within the city. This may have deterred municipal officials from taking part. Furthermore, the municipal development planning processes in South Africa do not readily make provision for shared knowledge and knowledge negotiation processes since stakeholder participation processes were already entrenched in post-1994 legislative reforms.

With regard to the focus on an "environmental controversy", it proved difficult to focus on a single environmental controversy in a complex, urban, multi-use space. The supporting and framing literature, and the case in the UK, focussed on a known environmental impact (flooding), which was socially and politically relevant (Lane et al., 2011). In the Golden Mile experiment, there were multiple environmental controversies of lower political relevance but high environmental importance. The beach water quality focus was important but not urgent, and political and social relevance should drive the work of future competency groups.

A weakness of the nested processes and institutions for ICM in South Africa, even though there are many directives to the contrary, is the lack of thoughtful and authentic stakeholder and civil 
Table 2 Data produced and the resulting increase in the body of knowledge relating to the management of the marine water quality of the coastal area of the Durban Golden Mile ${ }^{4}$.

\section{Data produced}

Individual and group maps depicting the places people "liked" on the beach and the natural, or social elements or "things" that have been lost or were missing.

Group maps of issues and other data (e.g., stakeholder lists, key issues) produced during the pilot phase by knowledge type (workshop reports).

Individual and group data related to question relating to values e.g. what do you understand by the word "water quality"? (captured on cards and flipcharts).

Video and photographic recordings of all meetings, transcriptions of the conversations, and photographs of all Photos of meetings.

Presentations by individuals related to the environmental controversies, group responses and questions (e.g. "Blue Flag" eco-labelling in South Africa, the importance of tourism, hydrodynamic modelling study of Durban Bight, water quality monitoring).

Others data and the resulting body of knowledge yet to analysed:

- Records of individual concepts of what the "coastal management" vision of the study area should be resulting in a vision formulated by the group.

- Records of individual opinions on the state of the coast of the study area resulting in an integrated statement on the social, environmental and financial state of the coast. See for example Supplementary Fig. 5.

- Interview responses of potential competency group members resulting in a profile of tacit knowledge holders (team).

- Cards, flipcharts, individual response forms (such as the responses to the modelling presentation).

- Post-meeting reports for each competency group meeting resulting in a preliminary analysis (e.g. discourse of loss and regret).

- Local team meeting minutes, project team meeting minutes, project evaluation by the group. See Supplementary Tables 3 and 4. society participation. The initial stakeholder engagement during the formulation phase demonstrated that there are a range of "non-regular" or "invisible" actors that should contribute to any public process of integrated (and inclusive) management of a high-value and common resource such as the coastal public property (see Scott and Oelofse, 2005). Furthermore, the theoretical argument was that competency group members were not stakeholders, participating to secure their interests, but rather knowledge-holders included to contribute to the co-production of knowledge of the knowledge controversy. The competency group as an "experimental research apparatus" (Braun, 2015a, 104) demonstrates how "a situation is able to affect its participants, and in so doing, generate new ideas, new powers, and perhaps new possibilities" for knowing and acting differently (Whatmore and Landstrom, cited in Braun, 2015a).

Co-production of knowledge offers new possibilities for more inclusive and transformative type of knowledge for decisionmaking (Lotz-Sisitka et al., 2015). It is argued here that, when produced with and by coastal managers, the knowledge outcomes hold the promise of more socially useful and appropriate basis for action and implementation (van Breda and Swilling, 2019). The process, however, has many challenges. Evidence shows that members of the competency group were still deeply embedded in the "stakeholder model" of public participation, the Public Education Model (PEM) dominated by scientific experts with only commentary by societal actors (Callon, 1999). It took some time in the competency group process to begin eroding this model of engagement where participants' interests are defended rather than a process of collaborative engagement and sharing and coproducing of knowledge (Research Team workshop, 27-29 May, 2014). However, this experiment has demonstrated a more democratic approach for knowledge production to contribute to and enrich the people-centred and pro-poor philosophy of the ICM Act and enhance social learning.
Proposition 2 Appropriateness of the process and method of competency groups

Owing to funding restrictions, the competency group process proved to be too short ( 6 meetings in 12 months). This did not allow enough time to pass the ownership of facilitation to the knowledge holders, nor adequate engagement to take place to form a "community of practice", nor for a "common pool of shared information and understanding" to be produced. Much of the data and information collected during the project remaining unexamined even though five Masters theses were produced by the students working as research assistant on the project.

The competency group method was experimental in nature with an unpredictable outcome. Whatmore and Landstrom (2011) call the actors in such type of experiments "apprentices". The "matter of concern" or controversy focused on beach water quality, and all group members were committed to engaging, not necessarily to promote their interests or their knowledge but to co-produce knowledge. Members were selected based on the variety of the knowledges that they held resulting in "experts" working with "non-experts" (see Stassart, 2008). Since none of the members were considered to hold all three types of knowledge, the term "apprentice" is appropriate, as through the process all the participants widened their own knowledge-holdings through mutual learning and became open to alternative viewpoints (see Callon, 1999; Kompridis, 2011). It was apparent that mutual learning had begun to take place with nascent receptivity to other viewpoints emerging.

The large income and education discrepancies that exist in the local context, and the legacy of racial and economic segregation and persisting social and spatial inequality made it difficult to convene a competency group as that reported in the literature (Whatmore, 2009; Lane et al., 2011). Coastal management, its institutions and instruments, even at local level, remain largely inaccessible to tacit knowledge holders. This remained a challenge 
throughout the project. The competency group was composed of "volunteers" and interested knowledge-holders who accepted the invitation. From early on in the project it became apparent that a number of tacit knowledge holder (also often small or informal business owners) could not or did not want to participate. Even though the option of compensation for their time was possible, they were not willing to take a risk on the opportunity costs of leaving their main source of income unattended to participate in our process.

The group itself was not mandated to operate within local policy and its legitimacy and accountability was only provided by the standing of its members. As an institution, it was not therefore possible to embed the outcomes into formal local policy processes stipulated by the ICM Act. By including municipal coastal officials, the aim was to enhance their receptivity to the value of more inclusive processes of knowledge production in the future (see Kompridis, 2011).

Group members were also deeply embedded in the stakeholder representation mode. They had been part of numerous public stakeholder participation workshops in the past, and originally assumed that their role was to promote their individual or sector interests. These assumptions were eroded during the project, but more time would have potentially enabled participants to move further beyond this entrenched stakeholder mind set and become more receptive to the views, opinions and knowledge of others. Knowledge holders became familiar with the request to contribute their knowledge and not argue for their interests in the discussions.

The project intent was to create a consistent co-production safe "space" and in doing so we adapted the activities to the structural realities of working in a society under transformation (Scott et al., 2019). Since the project was experimental, the workshops and methods used were designed iteratively, as the knowledge production process unfolded. In retrospect, we realised that we had been applying a combination of "science-society" models. The public debate model (PDM or stakeholder model; Callon, 1999) was explicitly avoided during planning process but could still be observed playing out e.g. the presentation of the hydraulic model of coastal waters presented by a modelling expert.

As previously mentioned, the didactic public education model (PEM) was also evident in the design of the project. The project team often requested the use of slide-show presentations to provide knowledge about some of the environmental controversies by members of the group, e.g. a presentation by the relevant municipal official about Blue Flag beach water quality guidelines, and a lecture on the testing of water quality in the laboratory (Competency Group Meeting 2). The didactic, conventional mode of learning remains a one-way knowledge transfer process with limited direct potential for co-production of knowledge. However, it was still useful as a "talking point" in the group and plenary discussions. This enhancing of receptivity to the knowledge of others and stimulating new ways of thinking about the environmental controversy became possible.

The use of the narrative or dialogic method (see Beausoleil, 2014) was most valuable as it allowed for all members, with a plurality of perspectives, to recall experiences and give voice to their values. The group work was managed by deliberately creating teams of knowledge holders from different backgrounds so that knowledge could be shared; different viewpoints aired and contentious issues raised ${ }^{6}$. For example, at the first meeting on the 16th floor of a hotel centrally located in the study area overlooking the beach, each person interpreted what they saw from their viewpoint when they looked out the window. This was the beginning of their journey of putting "their feet into others shoes" (Kompridis, 2011). The strength of the competency group method was that it provided "situated knowledge" from the non-academics in the group, which is critical in the process of creating useful and accessible knowledge for coastal management (Polk, 2015).

Proposition 3 Type and adequacy of knowledge produced

The project activities resulted in the capturing of data from a range of different knowledge types (Table 1). The availability of tacit knowledge was limited. At the onset of the experiment, it was assumed that individuals in the competency group possessed a specific type of knowledge (i.e. tacit, embedded and codified). However, during the experiment this assumption was contested by the group itself, and evident in the character and contribution of members at meetings. Even though there was a strong expression to include tacit knowledge, it became difficult to categorise tacit/experiential data as a type of knowledge produced by the group. Embedded and codified knowledge holders proposed that their contributions were a combination of their codified, embedded and experiential knowledge, suggesting a category of "hybrid knowledge". This points to their receptivity to considering all viewpoints in knowledge production.

There was a distinct absence of tacit indigenous and cultural knowledge on the study area. There was, however, a rich array of technical knowledge produced (for coastal management). For example, there was a keen understanding of the loss of surfing as an economic driver due to the building of new piers and the sand pumping scheme to maintain the beach width of the Golden Mile. The consequence of the surfing-character of Durban resulted in a loss of revenue for the city (Meeting 2 and 5 Transcriptions). Thus, overall there was an imbalance in the representation of knowledge types, potentially affecting the character of the coproduced knowledge.

The literature provided little guidance on methods and activities to use in each meeting. The project team had to develop methods iteratively ahead of each meeting based on their reflections of the previous meeting. While not completely ad hoc, there was no clear "roadmap" to anticipate and design the overall knowledge collection strategy. Even though experimental in nature, the competency group concluded with useful co-produced knowledge beginning to emerge. The uniformities that emerged from the group when questioned on value systems underpinning the need for good beach water quality (see Table 1, Meeting 3)-despite their knowledge preference-were especially useful in understanding some of the societal dynamics.

\section{Discussion}

The transdisciplinary approach, and the social experiment with competency groups turned out to be challenging but rewarding. The large volume of data and information generate during the project where difficult to interpret during the project period and with the funding available. The testing of the propositions resulted in the identification of both strengths and weaknesses of the co-production process and the effort to negotiate new knowledge by way of competency group (Fig. 2). Our reflections on the process and the data generated identified more weaknesses than strengths, and this itself is a challenge to future transdisciplinary projects.

The project provided an interesting yet challenging opportunity to experiment with different approaches to understand and address real-world management challenges of the Golden Mile. The two primary investigators were both residents of the city and also both enjoy the social space of the beachfront. However, there were underlying complexity in the social and community structure of the space that was not apparent when the project was conceptualised. Primarily, experiment showed that it is difficulty to access tacit knowledge-holders. It did however allow for the "opening up" of scientific knowledge about environmental controversies, particularly that of poor beach water quality in the 


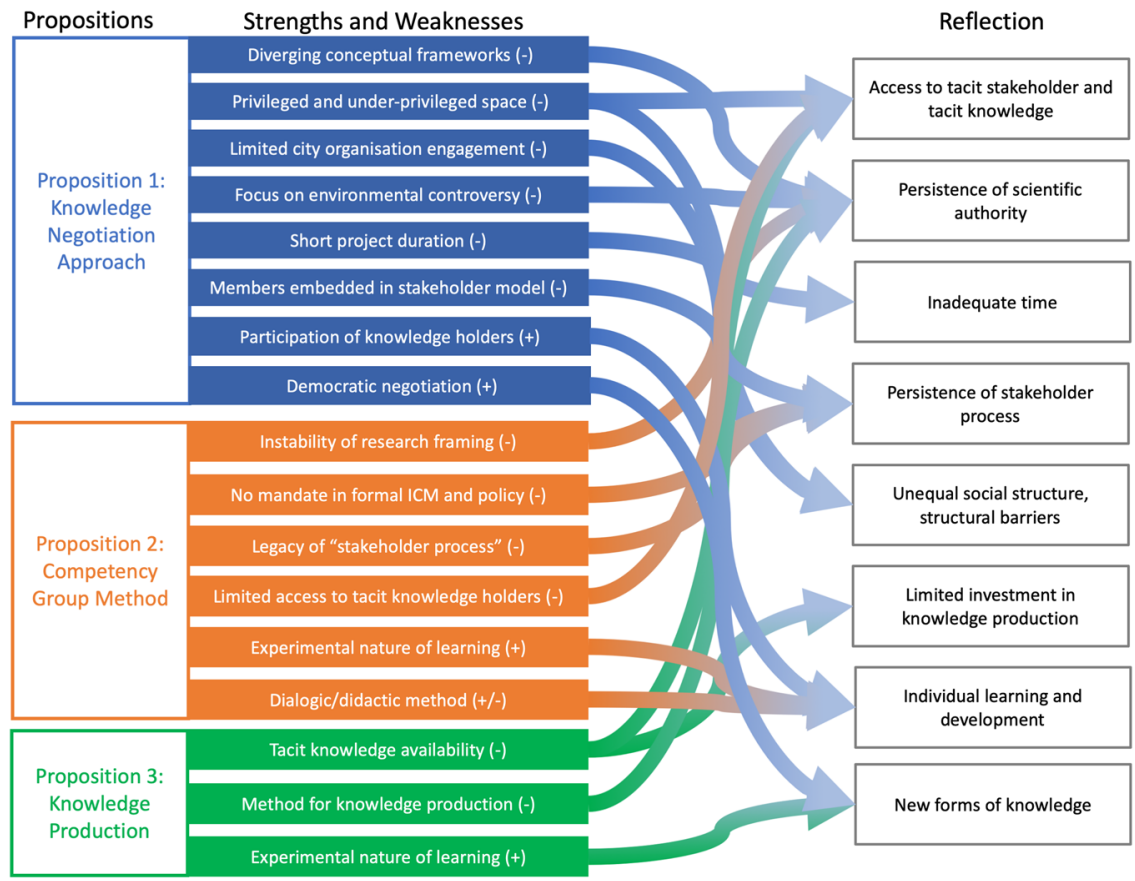

Fig. 2 Observations and reflections on the strengths $(+)$ and weaknesses $(-)$, ordered by the propositions of the study on the use of competency groups, as part of a transdisciplinary approach, to generate new knowledge for coastal management.

specific context of a city in a middle-income country. The bestowed equality of an individual's right to contribute knowledge, and knowledge-type selection of participants (technical, codified and tacit) created conditions that were very different from established stakeholder processes. The process unsettled the conventional norms of the "stakeholder process".

The benefits of a transdisciplinary approach were evident, but also the many challenges such an approach in the South African context, particularly the persistence of scientific authority over other forms of knowledge. The conditions required for transdisciplinarity and the proposed equality of knowledge types thus created tension in the research team, some of whom were more familiar with a normal disciplinary science of knowledge production (Funtowicz and Ravetz, 2003). There was an element of this tension within the competency group as well, especially between engineers and marine scientists and the idea of the equality of all data. This was visible but not pronounced. There remained an implied science positivist paradigm and it became clear that "levelling the playing fields", i.e. breaking down the power relationship of science and other forms of knowledge would require more time than what was allowed for in the project.

The allocation of time to allow for mutual learning and trust was not sufficient (i.e., funding constraints). Beach water quality and its governance is a complex multi-dimensional topic. The highly inclusive and engaging social process made it challenging to manage both time and project budget. A true transdisciplinary approach will require more budget, time and effort that would be conventionally allocated to normal science consultation and stakeholder engagement (see Holm et al., 2013; Lang et al., 2012; Stokols, 2006). The outcomes of the knowledge produced and the process undertaken need to be acknowledged as valuable (see Polk, 2015). It is through mutual learning that to co-production can be realised, and a new kind of knowledge through a more "radical form of scientific method" with the "redistribution of expertise" at its core (Whatmore, 2009).

Within the South African context there were distinct and persistent structural barriers, linked to apartheid, that prevented racial, social and economic equality of knowledge holders. Our efforts in enrolling knowledge holders into the competency group revealed that the holders of codified, embedded and tacit coastal knowledge of the coastal zone of eThekwini over two decades post-1994, are still predominantly from the white and Indian minorities. Despite being aware of a range of African knowledge holders who live and work in the area, the methods used by the research team failed to access their knowledge. The Councillor for Ward 26 noted that African people have no attachment to the beachfront coastal zone as they had been denied from using the beaches during the Apartheid regime (Meeting 1: 12th March 2015). He declined to attend any further meetings.

Another prominent structural barrier was the universal familiarity and easy acceptance of the established stakeholder processes (embedded in legislation ${ }^{7}$ ) that grants undue power to facilitators, especially if, and most often by virtue of access to and familiarity to technical or scientific knowledge. This project was intentional in attempting equity and equality of experimental conditions but even so, the mode of engagement kept reverting to conventional stakeholder approach with participants providing knowledge to suit their interest.

The limited investment in the knowledge production by the municipality and the rigid institutional structures formed a barrier for integrating knowledge produced by the competency group into the municipal decision-making process. The small amount of research funding (the original amount requested being substantially cut), the limited investment in the project by the municipality and the rigid institutional structures formed a barrier for integrating new knowledge into the municipal decisionmaking process.

The bulk of the knowledge contributed and negotiated by the competency group members were related to the technical elements of beach water quality relating to engineering/scientific knowledge (e.g., required understanding of sources, pollutant loading, transport and fate of pollutants, and health impacts). However, the importance of building trust and respect, two intangibles, were evident throughout the experiment. These 
intangibles resulted in confidence and insight, and a much clearer understanding of personal or individual value systems related to beach water quality. This recognition of the differences in the perception of how individuals value their environment was enlightening and important. Participants themselves acknowledged that beach water quality relative to the perspective of the observer-and this inclusion of individual values in knowledge was, for the project team, a breakthrough.

As a social experiment, transdisciplinary research would benefit from adopting a pragmatist approach to reflexivity. Such an approach relates reflexivity to collective processes of problem framing and problem solving through joint experimentation and social learning that directly involve the scientific and extrascientific expertise (Popa et al., 2015). These processes need to “... combine conventional consensus-oriented deliberative approaches to reflexivity with more open-ended, action-oriented transformative approaches."

The logistical and practical arrangement for the competency group meetings were substantial and could have well played a role in the ability and willingness of participants to contribute. The narrative approach, and the telling of stories worked well, and allowed for the establishment of a nuanced understanding of perspectives of others. The procurement framework of the project did not make sufficient allowances to materially support tacit knowledge holders to remain involved. The offset of income lost due to attending competency group meetings could have secured a wider diversity of stakeholders. The selection of venues and the set-up of the meeting environment should avoid the methods used in the "stakeholder model" meeting.

\section{Conclusion}

The social experimentation within a competency group provided a novel lens into a potentially very different, rewarding and imminently useful approach of co-producing knowledge for coastal governance, especially in a middle-income country where the social and political context is complex. It is recommended that transdisciplinary approaches must be applied in knowledge production for policy-making, to break down the many structural barriers that hinder the use and integration of, experiential, local and indigenous knowledge into the current predominantly scientific and technical knowledges used in policy-making. Such approaches take time, which requires additional research budget, which is difficult to source from science-led national funding agency in a middle-income/developing country context. Experimenting with a competency group, as a form of transdisciplinarity, resulted in a "constructive challenges" of achieving some of the objectives of the project. This work offers a reflection on the substantive challenges, and the promise of transdisciplinarity to address wicked problems.

\section{Data availability}

The datasets generated during and/or analysed during the current study are housed at the corresponding authors' primary institution in South Africa and are also available from the corresponding author on reasonable request.

Received: 11 February 2021; Accepted: 17 August 2021;

Published online: 07 September 2021

\section{Notes}

1 This study acknowledges and generally follows the terminology of the "knowledge" or "information hierarchy" (Rowley 2007) and the relationship and flow between scientific data, interpreted to produce information and then contextualised as knowledge. This forms the basis for our distinction between the term data, information and knowledge. Many academic references use a looser definition of the terms in which case we retain the word used in the information source. Our analysis retains the meaning of and differentiation between data, information and knowledge.

2 See Ryedale Flood Research Group, 2008 Making Space for People in Flood Risk Management http://knowledge-controversies.ouce.ox.ac.uk/ryedaleexhibition/ Making_Space_for_People.pdf

3 This method differed significantly from that of the UK Competency Group, which consisted of enrolling volunteers from a small village.

4 It is important to note that the groups consisted of members who provided tacit, embedded and codified knowledge. The dialogue and discussion thus co-produced knowledge about the issue at hand.

5 Race and ethnicity remain an important identifier of South African politics and society in general especially in the analysis of inequality. The use of the word "black", "white", "coloured" and "Indian" are therefore used as such in this manuscript.

6 See Table 1 in Scott and Taylor, 2019.

7 South African Constitution (1996) and the National Environmental Management Act (1998) (NEMA) stipulates and need for public participation of all stakeholders in environmental decision-making who would be affected by the decision. They have a stake in the results of the decision.

\section{References}

Arnott JC, Neuenfeldt RJ, Lemos MC (2020) Co-producing science for sustainability: can funding change knowledge use? Glob Environ Chang 60:101979. https://doi.org/10.1016/j.gloenvcha.2019.101979

Beausoleil E (2014) The politics, science, and art of receptivity. Ethics Glob Polit 7:19-40. https://doi.org/10.3402/egp.v7.23231

Bernstein JH (2015) Transdisciplinarity: a review of its origins, development, and current issues. J Res Pract 11:1-20, Article R1.Retrieved from http:// jrp.icaap.org/index.php/jrp/article/view/510/436.

Bremer S, Meisch S (2017) Co-production in climate change research: reviewing different perspectives. Wiley Interdiscip Rev Clim Chang 8:1-22. https:// doi.org/10.1002/wcc.482

Bulkeley H, Marvin S, Palgan YV et al. (2018) Urban living laboratories conducting the experimental city? Eur Urban Reg Stud 26:317-335. https://doi.org/ $10.1177 / 0969776418787222$

Callon M (1999) The role of lay people in the production and dissemination of scientific knowledge. Sci Technol Soc 4:81-94. https://doi.org/10.1177/ 097172189900400106

Cann HW, Raymond L (2018) Does climate denialism still matter? The prevalence of alternative frames in opposition to climate policy. Env Polit 27:433-454 https://doi.org/10.1080/09644016.2018.1439353

Celliers L, Colenbrander DR, Breetzke T, Oelofse G (2015) Towards increased degrees of integrated coastal management in the City of Cape Town, South Africa. Ocean Coast Manag 105:138-153. https://doi.org/10.1016/j.ocecoaman.2014.11.005

Celliers L, Rosendo S, Coetzee I, Daniels G (2013) Pathways of integrated coastal management from national policy to local implementation: Enabling climate change adaptation. Mar Policy 39:72-86. https://doi.org/10.1016/ j.marpol.2012.10.005

Choi BCK, Pak AWP (2007) Multidisciplinarity, interdisciplinarity, and transdisciplinarity in health research, services, education and policy: 2. Promotors, barriers, and strategies of enhancement. Clin Investig Med 30:224. https:// doi.org/10.25011/cim.v30i6.2950

Clarke B, Stocker L, Coffey B et al. (2013) Enhancing the knowledge-governance interface: coasts, climate and collaboration. Ocean Coast Manag 86:88-99. https://doi.org/10.1016/j.ocecoaman.2013.02.009

Cvitanovic C, Hobday AJ, van Kerkhoff L et al. (2015) Improving knowledge exchange among scientists and decision-makers to facilitate the adaptive governance of marine resources: a review of knowledge and research needs. Ocean Coast Manag 112:25-35. https://doi.org/10.1016/j.ocecoaman.2015.05.002

Dewulf A, Klenk N, Wyborn C, Lemos MC (2020) Usable environmental knowledge from the perspective of decision-making: the logics of consequentiality, appropriateness, and meaningfulness. Curr Opin Environ Sustain 42:1-6. https://doi.org/10.1016/j.cosust.2019.10.003

Funtowicz SO and Ravetz JR (2003) Post-Normal Science. In: International Society for Ecological EconomicsInternet Encyclopaedia of Ecological Economics. Retrieved from http://isecoeco.org/pdf/pstnormsc.pdf.

Glavovic BC (2000) A new coastal policy for South Africa. Coast Manag 28:261-271. https://doi.org/10.1080/089207500408665

Glavovic BC, Boonzaier S (2007) Confronting coastal poverty: building sustainable coastal livelihoods in South Africa. Ocean Coast Manag 50:1-23. https:// doi.org/10.1016/j.ocecoaman.2006.07.001

Hessels LK, van Lente H (2008) Re-thinking new knowledge production: a literature review and a research agenda. Res Policy 37:740-760. https://doi.org/ 10.1016/j.respol.2008.01.008

Holm P, Goodsite ME, Cloetingh S et al. (2013) Collaboration between the natural, social and human sciences in Global Change Research. Environ Sci Policy 28:25-35. https://doi.org/10.1016/j.envsci.2012.11.010 
Hulme M (2010) Problems with making and governing global kinds of knowledge. Glob Environ Chang 20:558-564. https://doi.org/10.1016/j.gloenvcha. 2010.07.005

Jagannathan K, Arnott JC, Wyborn C et al. (2020) Great expectations? Reconciling the aspiration, outcome, and possibility of co-production. Curr Opin Environ Sustain 42:22-29. https://doi.org/10.1016/j.cosust.2019.11.010

Jentoft S, Chuenpagdee R (2009) Fisheries and coastal governance as a wicked problem. Mar Policy 33:553-560. https://doi.org/10.1016/j.marpol. 2008.12.002

Jukuda A (2015) Power politics in coastal governance: an investigation of competency groups. University of KwaZulu-Natal, Durban

Klein JT (2013) The transdisciplinary moment(um) Integr Rev 9:189-199

Klein JT (2014) Discourses of transdisciplinarity: looking back to the future. Futures 63:68-74. https://doi.org/10.1016/j.futures.2014.08.008

Knight E, Tsoukas H (2019) When fiction trumps truth: what 'post-truth' and 'alternative facts' mean for management studies. Organ Stud 40:183-197. https://doi.org/10.1177/0170840618814557

Kompridis N (2011) Receptivity, possibility, and democratic politics. Ethics Glob Polit 4:255-272. https://doi.org/10.3402/egp.v4i4.14829

Lane SN (2014) Acting, predicting and intervening in a socio-hydrological world. Hydrol Earth Syst Sci 18:927-952. https://doi.org/10.5194/hess-18-927-2014

Lane SN, Odoni N, Landström C et al. (2011) Doing flood risk science differently: an experiment in radical scientific method. Trans Inst Br Geogr 36:15-36. https://doi.org/10.1111/j.1475-5661.2010.00410.x

Lang DJ, Wiek A, Bergmann $\mathrm{M}$ et al. (2012) Transdisciplinary research in sustainability science: practice, principles, and challenges. Sustain Sci 7:25-43. https://doi.org/10.1007/s11625-011-0149-x

Latulippe N, Klenk N (2020) Making room and moving over: knowledge coproduction, Indigenous knowledge sovereignty and the politics of global environmental change decision-making. Curr Opin Environ Sustain 42:7-14. https://doi.org/10.1016/j.cosust.2019.10.010

Lawrence RJ, Després C (2004) Futures of transdisciplinarity. Futures 36:397-405. https://doi.org/10.1016/j.futures.2003.10.005

Lotz-Sisitka H, Wals AEJE, Kronlid D, McGarry D (2015) Transformative, transgressive social learning: rethinking higher education pedagogy in times of systemic global dysfunction. Curr Opin Environ Sustain 16:73-80. https:// doi.org/10.1016/j.cosust.2015.07.018

Mach KJ, Lemos MC, Meadow AM et al. (2020) Actionable knowledge and the art of engagement. Curr Opin Environ Sustain 42:30-37. https://doi.org/10.1016/ j.cosust.2020.01.002

Max-Neef MA (2005) Foundations of transdisciplinarity. Ecol Econ 53:5-16. https://doi.org/10.1016/j.ecolecon.2005.01.014

Mitchell C, Cordell D, Fam D (2015) Beginning at the end: the outcome spaces framework to guide purposive transdisciplinary research. Futures 65:86-96. https://doi.org/10.1016/j.futures.2014.10.007

Nagy E, Ransiek A, Schäfer M et al. (2020) Transfer as a reciprocal process: How to foster receptivity to results of transdisciplinary research. Environ Sci Policy 104:148-160. https://doi.org/10.1016/j.envsci.2019.11.007

Norström AV, Cvitanovic C, Löf MF et al. (2020) Principles for knowledge coproduction in sustainability research. Nat Sustain 3:182-190. https://doi.org/ 10.1038/s41893-019-0448-2

Nursey-Bray MJ, Vince J, Scott M et al. (2014) Science into policy? Discourse, coastal management and knowledge. Environ Sci Policy 38:107-119. https:// doi.org/10.1016/j.envsci.2013.10.010

Ordner JP (2017) Community action and climate change. Nat Clim Chang 7:161-163. https://doi.org/10.1038/nclimate3236

Polk M (2015) Transdisciplinary co-production: designing and testing a transdisciplinary research framework for societal problem solving. Futures 65:110-122. https://doi.org/10.1016/j.futures.2014.11.001

Popa F, Guillermin M, Dedeurwaerdere T (2015) A pragmatist approach to transdisciplinarity in sustainability research: from complex systems theory to reflexive science. Futures 65:45-56. https://doi.org/10.1016/j.futures. 2014.02.002

Romero-Lankao P, Bulkeley H, Pelling M et al. (2018) Urban transformative potential in a changing climate. Nat Clim Chang 8:754-756. https://doi.org/ 10.1038/s41558-018-0264-0

Rosendahl J, Zanella MA, Rist S, Weigelt J (2015) Scientists' situated knowledge: Strong objectivity in transdisciplinarity. Futures 65:17-27. https://doi.org/ 10.1016/j.futures.2014.10.011

Rosendo S, Celliers L, Mechisso M (2018) Doing more with the same: A realitycheck on the ability of local government to implement Integrated Coastal Management for climate change adaptation. Mar Policy 87:29-39. https:// doi.org/10.1016/j.marpol.2017.10.001

Rowley J (2007) The wisdom hierarchy: representations of the DIKW hierarchy. J Inf Sci 33:163-180. https://doi.org/10.1177/0165551506070706

Rutjens BT, van der Linden S, van der Lee R, Zarzeczna N (2021) A group processes approach to antiscience beliefs and endorsement of "alternative facts.".
Gr Process Intergr Relations 24:513-517. https://doi.org/10.1177/ 13684302211009708

Sachs JD, Schmidt-Traub G, Mazzucato M et al. (2019) Six Transformations to achieve the sustainable development goals. Nat Sustain 2:805-814. https:// doi.org/10.1038/s41893-019-0352-9

Scholz RW, Steiner G (2015) The real type and ideal type of transdisciplinary processes: part I-theoretical foundations. Sustain Sci 10:527-544. https:// doi.org/10.1007/s11625-015-0326-4

Scott D, Oelofse C (2005) Social and environmental justice in South African cities: including "invisible stakeholders" in environmental assessment procedures. J Environ Plan Manag 48:445-467. https://doi.org/10.1080/09640560500067582

Scott D, Taylor A (2019) Receptivity and Judgement: expanding ways of knowing the climate to strengthen the resilience of cities. Future Resilience for African CiTies and Lands (FRACTAL). Retrieved from https://www.fractal.org.za/ wp-content/uploads/2019/02/Scott-D-and-Taylor-A-Receptivity-andJudgement-web.pdf.

Simon D, Palmer H, Riise J et al. (2018) The challenges of transdisciplinary knowledge production: from unilocal to comparative research. Environ Urban 30:481-500. https://doi.org/10.1177/0956247818787177

Sowman M, Malan N (2018) Review of progress with integrated coastal management in South Africa since the advent of democracy. African J Mar Sci 40:121-136. https://doi.org/10.2989/1814232X.2018.1468278

Stassart PM (2008) Running an interdisciplinary competency group. Centre for Rural Economy. Newcastle University

Stock P, Burton RJF (2011) Defining terms for integrated (multi-inter-trans-disciplinary) sustainability research. Sustainability 3:1090-1113. https://doi.org/ $10.3390 /$ su3081090

Stokols D (2006) Toward a science of transdisciplinary action research. Am Community Psychol 38:63-77. https://doi.org/10.1007/s10464-006-9060-5

Swilling M (2014) Rethinking the science-policy interface in South Africa: Experiments in knowledge co-production. S Afr J Sci 110:1-7

Turnhout E, Metze T, Wyborn C et al. (2020) The politics of co-production: participation, power, and transformation. Curr Opin Environ Sustain 42:15-21. https://doi.org/10.1016/j.cosust.2019.11.009

van Breda J, Swilling M (2019) The guiding logics and principles for designing emergent transdisciplinary research processes: learning experiences and reflections from a transdisciplinary urban case study in Enkanini informal settlement, South Africa. Sustain Sci 14:823-841. https://doi.org/10.1007/s11625-018-0606-x

van Ewijk E, Baud I (2009) Partnerships between Dutch municipalities and municipalities in countries of migration to the Netherlands; knowledge exchange and mutuality. Habitat Int 33:218-226. https://doi.org/10.1016/ J.HABITATINT.2008.10.014

van Heerden P (2015) The politics of knowledge: case study of the management of beach water quality in Durban, Souh Africa. University of KwaZulu, Natal, Durban

Vera C (2018) Farmers transformed how we investigate climate. Nature 562:9-9. https://doi.org/10.1038/d41586-018-06856-6

Vogel C, Scott D, Culwick CE, Sutherland C (2016) Environmental problemsolving in South Africa: harnessing creative imaginaries to address 'wicked' challenges and opportunities. South African Geogr J 98:515-530. https:// doi.org/10.1080/03736245.2016.1217256

Whatmore SJ (2009) Mapping knowledge controversies: science, democracy and the redistribution of expertise. Prog Hum Geogr 33:587-598. https://doi.org/ $10.1177 / 0309132509339841$

Whatmore SJ, Landström C (2011) Flood apprentices: an exercise in making things public. Econ Soc 40:582-610. https://doi.org/10.1080/03085147.2011.602540

\section{Acknowledgements}

The CSIR in partnership with University of KwaZulu-Natal initiated a project within the context of the South African Global Change Grand Challenge and the Global Change (GCGC), Society and Sustainability Research Programme (SSRP) funded by the Department of Science and Technology. The project entitled "Negotiation of Knowledge for Coastal Governance" (Grant No. 78643) was undertaken from 2012-2017. Dr. Michelle Audouin from the CSIR is acknowledged for her contribution to the project and the review of the manuscript. Students Tazkiyyah Amra, Andisiwe Jukuda, Ndoda Zondo, Mathenjwa Mxolisi, and Paul van Heerden from the School of Built Environment and Development Studies, University of KwaZulu-Natal were funded by the Grant for their Masters studies and are thanked for their dedicated work as Research Assistants. We would like to acknowledge all participants of the Coastal Competency Group for their commitment to the process, their enthusiasm and for sharing their knowledge. The administrative and logistical assistance of Tarryn Newman and technical assistance of Paul van Heerden (both CSIR) are also gratefully acknowledged.

\section{Funding}

Open Access funding enabled and organized by Projekt DEAL. 


\section{Competing interests}

The authors declare no competing interests.

\section{Additional information}

Supplementary information The online version contains supplementary material available at https://doi.org/10.1057/s41599-021-00887-7.

Correspondence and requests for materials should be addressed to Louis Celliers.

Reprints and permission information is available at http://www.nature.com/reprints

Publisher's note Springer Nature remains neutral with regard to jurisdictional claims in published maps and institutional affiliations. (c) (i) Open Access This article is licensed under a Creative Commons Attribution 4.0 International License, which permits use, sharing, adaptation, distribution and reproduction in any medium or format, as long as you give appropriate credit to the original author(s) and the source, provide a link to the Creative Commons license, and indicate if changes were made. The images or other third party material in this article are included in the article's Creative Commons license, unless indicated otherwise in a credit line to the material. If material is not included in the article's Creative Commons license and your intended use is not permitted by statutory regulation or exceeds the permitted use, you will need to obtain permission directly from the copyright holder. To view a copy of this license, visit http://creativecommons.org/ licenses/by/4.0/.

(C) The Author(s) 2021 